\title{
Variasi Ketebalan Arang Cangkang Biji Karet dengan Metode Filtrasi Downflow Dalam Penurunan Parameter Fe Air Tanah Dalam
}

\author{
Andri Rhomadon Ritonga, Marhadi* \\ Program Studi Teknik Lingkungan Universitas Batanghari \\ *e-mail : marhadi54@yahoo.co.id
}

\begin{abstract}
ABSTRAK
Sumber daya air secara garis besar meliputi air permukaan dan air tanah. Air permukaan akan lebih mudah tercemar dibandingkan dengan air tanah, karena air permukaan lebih mudah terkontaminasi dengan sumber pencemaran sehingga masyarakat menggunakan air yang bersumber dari air tanah dalam. Kota Jambi khususnya daerah Kenali Asam Atas, termasuk dalam kawasan perumahan dengan kepadatan sedang kurang lebih \pm 6.903 Ha. cakupan wilayah pelayanan PDAM masih $2 \%$, dari cakupan wilayah pelayanan sebesar 10965 SR. Tujuan dari penelitian ini dapat menurunan parameter Fe dan $\mathrm{pH}$ pada air tanah dalam dengan menggunakan metode filtrasi downflow dan aerasi pada variasi ketebalan arang cangkang biji karet dengan metode filtrasi dan variasi waktu pengolahan pada proses aerasi menggunakan bubble aerator. Hasil dari proses metode filtrasi downflow menggunakan variasi ketebalan arang cangkang biji karet $15 \mathrm{~cm}$ dan $30 \mathrm{~cm}$ untuk parameter Fe sebesar 0,302 mg/l dan $\mathrm{pH}$ sebesar 5,08, sementara pada proses pengolahan aerasi menggunakan variasi waktu pengolahan 30 menit dan 60 menit untuk parameter Fe sebesar 0,354 mg/l dan $\mathrm{pH}$ sebesar 5,23.
\end{abstract}

Kata Kunci : Air tanah dalam; Cangkang biji karet; Filtrasi. ABSTRACT

Water resources generally cover surface and ground water. Surface water will be more easily polluted than ground water, because surface water is more easily contaminated with sources of pollution so that people use water sourced from deep ground water. In Jambi city particular the Kenali Asam Atas area, is included in a residential area with a moderate density of approximately \pm 6,903 Ha. PDAM service area coverage is still 2\%, from the service area coverage of $10965 \mathrm{SR}$. The purpose of this study was to reduce $\mathrm{Fe}$ and $\mathrm{pH}$ parameters in deep groundwater using downflow and aeration filtration methods on variations in thickness of rubber seed shell charcoal by filtration method and variation of processing time in the aeration process using bubble aerator. The results of the downflow filtration method using variations in the thickness of $15 \mathrm{~cm}$ and $30 \mathrm{~cm}$ rubber seed shell charcoal for Fe parameters of $0.302 \mathrm{mg} / 1$ and $\mathrm{pH}$ of 5.08 , while in the aeration treatment process using a variation of processing time of 30 minutes and 60 minutes for Fe parameters amounting to $0.354 \mathrm{mg} / 1$ and $\mathrm{pH}$ of 5.23.

Keywords: Deep ground wate; $r$ Filtration; Rubber seed shell.

\section{Pendahuluan}

Sumber daya air secara garis besar meliputi air permukaan dan air tanah. Air permukaan akan lebih mudah tercemar dibandingkan dengan air tanah, karena air permukaan lebih mudah terkontaminasi dengan sumber-sumber pencemaran. Sebagian besar masyarakat menggunakan air yang bersumber dari air tanah, baik air tanah dangkal maupun air tanah dalam (Cut Khairunnisa: 2012 ). Saat ini pencemaran air membuat masyarakat yang hidup baik di pedesaan maupun di perkotaan kesulitan untuk mendapatkan air bersih. Ini dapat dilihat pada hasil uji awal di Laboratorium di Dinas Lingkungan Hidup (DLH) Provinsi Jambi, kadar logam besi (Fe) sebesar 0,527 $\mathrm{mg} / \mathrm{l}$ dan mangan (Mn) sebesar $<0,01 \mathrm{mg} / \mathrm{l}$.
Sesuai dengan Peraturan Daerah Kota Jambi Nomor 09 Tahun 2013. Rencana Tata Ruang Wilayah Kota Jambi tahun 2013-2033, pada paragraf 2 kawasan peruntukan perumahan sebagai mana dimaksud dalam pasal 55, Pengembangan permukiman warga di wilayah Kecamatan Kota Baru, Kota Jambi khususnya daerah Kenali Asam Atas, termasuk dalam kawasan perumahan dengan kepadatan sedang kurang lebih $\pm 6.903 \mathrm{Ha}$.

Kota Jambi termasuk dalam wilayah dengan kepadatan sedang, akan tetapi pelayanan akan air bersih Menurut PDAM Tirta Mayang Kota Jambi cakupan wilayah pelayanan PDAM khususnya di Kecamatan Kota Baru, daerah Kenali Asam Atas masih $2 \%$, dari cakupan wilayah pelayanan Kecamatan Kota Baru sebesar 10965 SR. Oleh 
karena tujuan dari penelitian ini untuk mengetahui seberapa besar penurunan parameter Fe dan $\mathrm{pH}$ pada air tanah dalam dengan menggunakan metode filtrasi downflow dan aerasi dan untuk mengetahui variasi ketebalan arang cangkang biji karet pada proses filtrasi dan mengetahui variasi waktu pada proses aerasi menggunakan bubble aerator;

Air tanah dalam adalah air hujan yang meresap kedalam tanah lebih dalam lagi mealui proses absorpsi serta filtrasi oleh batuan dan mineral di dalam tanah. Sehingga berdasarkan prosesnya air tanah dalam lebih jernih dari air tanah dangkal (Kumalasari, 2011).

Untuk proses filtrasi secara fisik cangkang buah biji karet memiliki ciri ini sebagai tumbuhan yang berlignin Selain pemanfaatannya yang masih kurang optimal, jika dibandingkan dengan bagian buah lainnya, bagian cangkang termasuk bagian yang mengandung lignin yang cukup banyak, sehingga bagian ini cukup potensial untuk diolah menjadi produk karbon aktif yang sangat bermanfaat dan bernilai jual yang tinggi. Hal ini akan membuat cangkang buah bijikaret menjadi lebih termanfaatkan

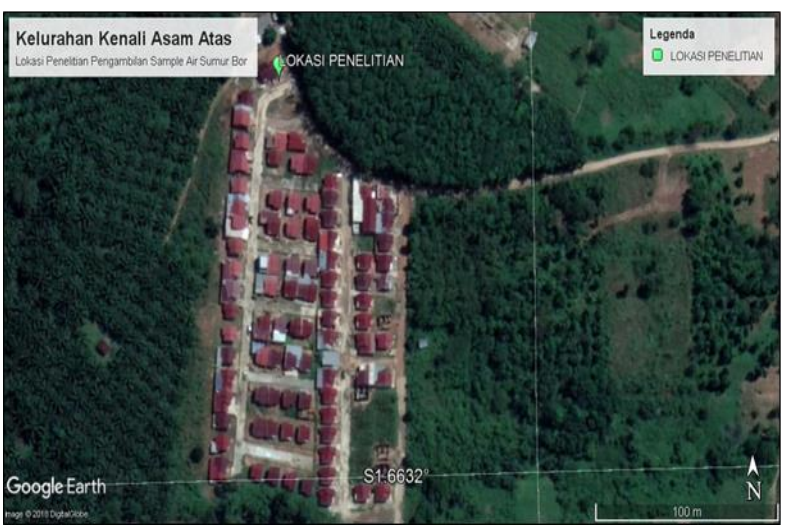

Gambar 1 Lokasi Pengambilan Sample Air Tanah Dalam (Google Earth Pro, 2018)

\section{METODE PENELITIAN}

Lokasi penelitian Perumahan Grand Namura Indah 2 Kelurahan Kenali Asam Atas Kecamatan Kota Baru Kota Jambi pada titik koordinat $1^{\circ}$ 39.695 'S dan $103^{\circ} 36.838^{\prime} \mathrm{T}$, dilakukan uji sampel awal dan akhir di laboraorium Dinas Lingkungan Hidup Provinsi Jambi

\subsection{Jenis Penelitian}

Penelitian ini bersifat eksperimental, hasil uji sampling dan pengolahan dilakukan dilaboratorium dengan membuat alat pengolahan dengan metode Filtrasi downflow dan Aerasi skala rumah tangga. Variasi bebas Ketebalan arang cangkang bijin karet dengan ketebalan $15 \mathrm{~cm}$ dan $30 \mathrm{~cm}$. Variasi waktu pada proses pengolahan aerasi yaitu 30 menit dan 60 menit dan variabel terikat yaitu air baku tanah dalam dengan parameter $\mathrm{Fe}, \mathrm{Mn}$ dan $\mathrm{pH}$.

\subsection{Bahan dan Alat}

Bahan baku yang digunakan pada uji pertama air tanah dalam 100 L, Pasir silika dengan Ketinggian $20 \mathrm{~cm}$, Kerikil dengan Ketinggian $30 \mathrm{~cm}$, Arang cangkang biji karet $15 \mathrm{~cm}$, Kapas akuarium dengan ketebalan $5 \mathrm{~cm}$ masing-masing per-media. Bahan baku yang digunakan pada uji yang kedua air tanah dalam $100 \mathrm{~L}$, pasir silika dengan Ketinggian $20 \mathrm{~cm}$, Kerikil dengan Ketinggian $30 \mathrm{~cm}$, arang cangkang biji karet dengan ketinggian $30 \mathrm{~cm}$, kapas akuarium dengan ketebalan $5 \mathrm{~cm}$ masing-masing per-media. Alat-alat yang digunakan dalam penelitian antara lain pipa PVC berdiameter $\varnothing 6$ inch dengan panjang 120 $\mathrm{cm}$, Bak penampung air baku kapasitas 160 liter, Pipa diameter $\varnothing 1$ inch sepanjang 2 meter; Elbow $\varnothing 1$ inch, Botol wadah sampel.

\section{Hasil dan Pembahasan}

Penelitian yang dilakukan pada alat filtrasi sistem (downflow) atau saringan pasir cepat, dengan pengujian pada sampel air baku dari sair tanah dalam dan hasil olahan dengan penambahan arang dari cangkang biji karet dan bubble aerasi, dilakukan dua kali pengujian pada sampel air baku dari air tanah dalam dengan detensi waktu percobaan pertama 30 menit dan yang kedua 60 menit dengan pengujian awal untuk menentukan parameter mangan (Mn), besi $(\mathrm{Fe})$, dan $\mathrm{pH}$.

\subsection{Hasil Pemeriksaan Air Tanah Dalam Sebelum Proses Pengolahan}

Hasil pengujian sampel awal air baku air tanah dalam menunjukkan diatas baku mutu yaitu besi (Fe), Mangan (Mg) dan Derajat Keasaman (pH). Hasil uji parameter yang diuji disajikan pada Table 3.1 berikut ini.

Tabel 1 Hasil Pengujian awal sampel air tanah dalam

\begin{tabular}{ccccc}
\hline No & Parameter & Satuan & $\begin{array}{c}\text { Hasil Uji } \\
\text { Lab }\end{array}$ & $\begin{array}{c}\text { Standar Baku Mutu } \\
\text { PERMENKES/416/ } \\
1990\end{array}$ \\
\hline 1 & $\mathrm{Fe}$ & $\mathrm{mg} / \mathrm{l}$ & 0,527 & 0,3 \\
2 & $\mathrm{Mn}$ & $\mathrm{mg} / \mathrm{l}$ & $<0,01$ & 0,1 \\
3 & $\mathrm{pH}$ & & 5,94 & $6,5-8,5$ \\
\hline
\end{tabular}

Sumber: Hasil Uji Laboratorium DLH Provinsi Jambi, 2019 
Dari hasil uji sample awal air tanah dalam sebelum proses pengolahan dengan parameter Fe (besi) sebesar 0,527 mg/l, parameter Mn (mangan) sebesar 0,01 mg/l, parameter $\mathrm{pH}$ sebesar 5,94, pada standar baku mutu Permenkes No. 46 Tahun 1990 hanya Fe yang melebihi baku mutu sebesar $0,3 \mathrm{mg} / \mathrm{l}$.

\subsection{Variasi Ketebalan Arang Cangkang Biji Karet 15 cm dan Variasi Waktu 30 Menit}

Proses pengolahan dengan metode filtrasi downflow dan proses aerasi dengan ketebalan arang cangkang biji karet $15 \mathrm{~cm}$ dan variasi waktu selama 30 menit mampu menurunkan parameter Fe yang terdapat didalam air baku air tanah dalam sebesar 0,302 mg/l, dan pH sebesar 5,08. Hasil Penelitian sampel air tanah dalam dengen metode filtasi downflow dan aerasi ditampilkan dalam bentuk Tabel 3.2 .

Tabel 2. Tahap Pertama Uji Sampel Air Baku Air Tanah Dalam pada Pengolahan Alat Filtrasi dan Aerator

\begin{tabular}{clccc}
\hline No & Parameter & Satuan & Baku Mutu & Pengujian arang cangkang biji karet 15 cm dan Aerator 30 menit \\
\hline 1 & Besi (Fe) & $\mathrm{mg} / 1$ & 0,3 & 0,302 \\
2 & Mangan (Mn) & $\mathrm{mg} / 1$ & 0,1 & 0,317 \\
3 & $\mathrm{pH}$ & & $6,5-8,5$ & 5,08 \\
\hline
\end{tabular}

\subsection{Variasi Ketebalan Arang Cangkang Biji Karet $30 \mathrm{~cm}$ dan Variasi Waktu 60 Menit}

Proses pengolahan dengan metode filtrasi downflow dan proses aerasi dengan ketebalan arang cangkang biji karet $30 \mathrm{~cm}$ dan variasi waktu selama
60 menit mampu menurunkan parameter Fe yang terdapat didalam air baku air tanah dalam sebesar 0,354 mg/l, dan 5,23. Hasil Penelitian sampel air tanah dalam dengen metode filtasi downflow dan aerasi ditampilkan dalam bentuk Tabel 3.3.

Tabel 3. Tahap Kedua Uji Sampel Air Baku Air Tanah Dalam pada Pengolahan Alat Filtrasi dan Aerator

\begin{tabular}{ccccc}
\hline No & Parameter & Satuan & Baku Mutu & Pengujian arang cangkang biji karet 30 cm dan Aerator 60 menit \\
\hline 1 & Besi (Fe) & $\mathrm{mg} / \mathrm{l}$ & 0,3 & 0,354 \\
2 & Mangan $(\mathrm{Mn})$ & $\mathrm{mg} / 1$ & 0,1 & 0,171 \\
3 & $\mathrm{pH}$ & & $6,5-8,5$ & 5,23 \\
\hline
\end{tabular}

\subsection{Pembahasan}

\section{Parameter Besi (Fe)}

Hasil penelitian terhadap parameter $\mathrm{Fe}$ berdasarkan tabel 1, dan dibandingkan dengan hasil variasi pada tabel 3.2, dan tabel 3.3 terlihat telah terjadi penurunan pada variasi pertama setelah dilakukan pengolahan dengan waktu penyaringan cepat dan aerasi selama 30 menit dari uji awal air baku tanah dalam sebesar $0,527 \mathrm{mg} / 1$ menjadi 0,302 $\mathrm{mg} / \mathrm{l}$ akan tetapi pada pengujian kedua dengan durasi aerasi selama 1 jam meningkat menjadi $0,354 \mathrm{mg} / 1$,

Penurunan pada tahap pengolahan awal dan kenaikan pada tahap kedua parameter besi (Fe) dapat dilihat dalam Gambar 1

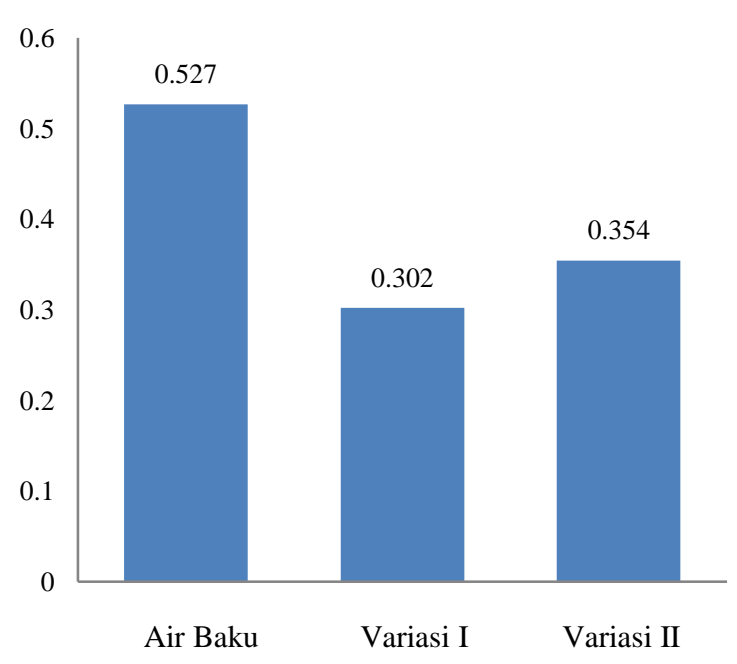

Gambar 2. Hasil Uji Paramater Fe 
Seperti yang dijelaskan pada gambar 3.1 bahwa dari penelitian yang dilakukan menghasilkan penurunan parameter parameter besi $(\mathrm{Fe})$ yang maksimal terlihat pada hasil uji pertama yaitu sebesar $0,302 \mathrm{mg} / \mathrm{l}$ dan uji kedua mengalami kenaikan sebesar $0,354 \mathrm{mg} / \mathrm{l}$, jika dibandingkan dengan baku mutu hasil variasi dari alat filtrasi dan aerasi untuk uji pertama masih sesuai standar baku mutu dan uji kedua diatas standa baku mutu.

\section{Parameter Mangan (Mn)}

Hasil penelitian terhadap parameter $\mathrm{Mn}$ (mangan) berdasarkan tabel 1, dan dibandingkan dengan hasil variasi pada tabel 2 , dan tabel .3 terlihat telah terjadi perubahan pada variasi pertama setelah dilakukan pengolahan dengan waktu penyaringan cepat dan aerasi selama 30 menit dari uji awal air baku tanah dalam sebesar $<0.01 \mathrm{mg} / 1$ menjadi 0.317 $\mathrm{mg} / \mathrm{l}$ akan tetapi pada pengujian kedua dengan durasi aerasi selama 1 jam meningkat menjadi $0.171 \mathrm{mg} / \mathrm{l}$,

Penurunan pada tahap variasi awal dan kenaikan pada tahap variasi kedua parameter Mn (Mangan) dapat dilihat dalam Gambar 2.

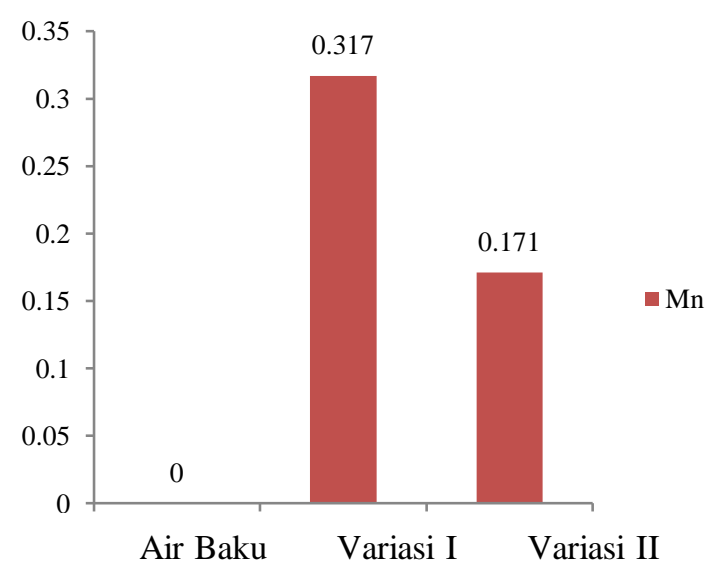

Gambar 3. Hasil Uji Parameter (Mn) Parameter

\section{derajat keasaman $(p H)$}

Hasil penelitian terhadap parameter $\mathrm{pH}$ dibawah baku mutu baik uji awal, variasi pengolahan pertama dan variasi pengolahan kedua, ini dilihat pada gambar hasil uji parameter $\mathrm{pH}$ pada variasi pertama sebesar 5,08 dan variasi kedua sebesar 5,23, pada pengolahan pada semua variasi tebal cangkang biji karet hanya mengalami penurunan sebesar $0,09 \%$, adapun gambar.3.

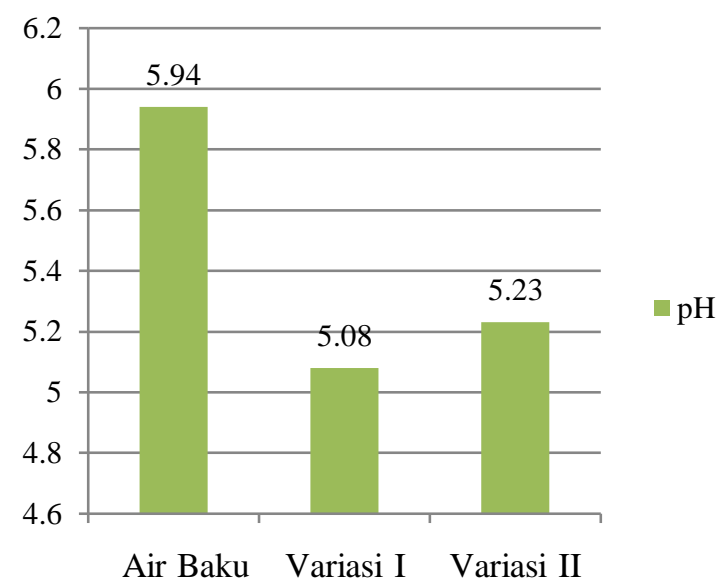

Gambar 4. Hasil Uji Parameter pH

\section{Hasil Uji Sample Air Tanah Dalam Sebelum dan Sesudah Melalui Proses}

Proses pengolahan air tanah dalam pada penelitian ini menggunakan metode filtrasi downflow dan proses aerasi menggunakan bubble aerator. Pada proses ini ini menggunakan variasi pengolahan yaitu variasi pada ketebalan arang cangkang biji karet 15 $\mathrm{cm}$ dan $30 \mathrm{~cm}$, sementara pada proses pengolahan aerasi menggunakan variasi waktu pengolahan 30 menit dan 60 menit. Dapat dilihat kualitas air baku setelah hasil pemeriksaan di laboratorium pada parameter $\mathrm{Fe} 0,527 \mathrm{mg} / \mathrm{l}$, parameter $\mathrm{Mn}<0,01 \mathrm{mg} / \mathrm{l}$, parameter $\mathrm{pH} 5,94$. Setelah dilakukan pengolahan dengan variasi media filtrasi arang cangkang biji karet $15 \mathrm{~cm}$ dan waktu proses pengolahan pada aerasi 30 menit mengalami perubahan hasil yaitu pada parameter Fe 0,302 mg/l, parameter Mn 0,317 mg/l, parameter $\mathrm{pH} 5,08$. Adapun hasil uji dapat dilihat pada gambar 4. 
Tabel 4. Hasil Uji Parameter Air Tanah Dalam

\begin{tabular}{lcccccc}
\hline No. & Parameter & Satuan & $\begin{array}{l}\text { Baku } \\
\text { Mutu }\end{array}$ & $\begin{array}{l}\text { Kualitas } \\
\text { Air Baku }\end{array}$ & \multicolumn{2}{c}{ Kualitas Air Treatment } \\
\hline & & & & & Variasi I & Variasi II \\
& $\mathrm{Fe}$ & $\mathrm{mg} / 1$ & 0,3 & 0,527 & 0,302 & 0,354 \\
2. & $\mathrm{Mn}$ & $\mathrm{mg} / \mathrm{l}$ & 0,1 & $<0,01$ & 0,317 & 0,171 \\
3. & $\mathrm{pH}$ & - & $6,5-8,5$ & 5,94 & 5,08 & 5,23 \\
\hline
\end{tabular}

Tabel 4 pada hasil parameter Fe, Mn dan $\mathrm{pH}$ pada proses pengolahan dengan variasi media filtrasi arang cangkang biji karet $30 \mathrm{~cm}$ dan variasi waktu pada proses pengolahan aerasi 60 menit mengalami perubahan pada parameter Fe $0,354 \mathrm{mg} / \mathrm{l}$, parameter Mn 0,071 mg/l, parameter pH 5,23.

\section{Kesimpulan}

Kesimpulan Hasil uji sample air baku tanah dalam dengan variasi arang dan waktu 30 menit hanya mampu menurunkan parameter $\mathrm{Fe}$ sebesar $0,302 \mathrm{mg} / \mathrm{l}$ dan pada variasi arang dan waktu 60 menit mengalami kenaikan parameter sebesar 0,354 $\mathrm{mg} / \mathrm{l}$.

\section{Daftar Pustaka}

Cut Khairunnisa. (2012). Pengaruh Jarak dan Konstruksi Sumur serta Tindakan Pengguna Air Terhadap Jumlah Coliform Air Sumur Gali Penduduk di Sekitar Pasar Hewan Desa Cempeudak Kecamatan Tanah Jambo Aye Kabupaten Aceh Utara Tahun 2012.

Effendi, H. (2003). Telaah Kualitas Air bagi Pengelolaan Sumber Daya dan Lingkungan Perairan. Cetakan Kelima. Yogjakarta : Kanisius.

Google Earth Pro. (2018).

Indriyati. (2008). Proses Pengolahan Limbah Organik Secara Koagulasi dan Flkulasi. Jakarta. Pusat Teknologi Lingkungan. Diakses dari:http://jurnal.pdii.lipi.go.id.

Kumalasari \& Satoto. (2011). Teknik Praktis Air Kotor Menjadi Air Bersih Hingga layak diminum. Laskar Aksara: Jakarta

Nusa Idaman Said (2010). Metoda Praktis Penghilangan Zat Besi dan Mangan di dalam Air Sumur.

Parulian, Alwin. (2009). Monitoring dan Analisis Kadar Aluminium ( $\mathrm{Al}$ ) dan Besi ( $\mathrm{Fe})$ Pada Pengolahan Air Minum PDAM Tirtanadi Sunggal. Medan : Pascasarjana - Universitas Sumatera Utara (USU).

PDAM Tirta Mayang. (2017). Jumlah Pelanggan tahun 2018. Jambi : PDAM Tirta Mayang.

PDAM Tirta Mayang. 2018. Kelompok Pelanggan PDAM Menurut Golongan Pelanggan 2018. Jambi : PDAM Tirta Mayang.

PERMENKES RI, (2010). Peraturan Menteri Kesehatan No. 416/MENKES/PER/IX/1990 tentang Syaratsyarat dan Pengawasan Kualitas Air, Jakarta : PERMENKES RI.
PERMENPU RI, (2007). Peraturan Menteri Pekerjaan Umum No. Kep- 18/PRT/M/2007 Tentang Penyelenggaraan Pengembangan Sistem Penyediaan Air Minum, Jakarta: PERMENPU RI.

Reni, D., Ellyta, S., Fadhilah, H., Laila, F. (2010). Kualitas air permukaan di Kampus II Universitas Bung Hatta, Konferensi Nasional PBKL-2010 kerjasama PSL Univ. Bung Hatta, PSLH Univ. Andalas dan PPKLH Univ. Negeri Padang. 4-5 November 2010, Padang.

Sanropie. (1984). Buku Pedoman Studi Penyediaan Air Bersih Akademi Penilik Kesehatan-Teknologi Sanitasi. Jakarta: Pusdiknakes

Setiawan. (2004). Polusi Air dan Udara. Yogyakarta: Kanisius

Sutrisno. (2010). Teknologi Penyediaan Air Bersih. Jakarta: Rineka Cipta

Wati. (2016). Kesehatan Masyarakat dan Teknologi Pengolahan Air. Jakarta: BPPT. 